\title{
IMPROVEMENT OF FOREST HEIGHT RETRIEVAL BY INTEGRATION OF DUAL- BASELINE POLINSAR DATA AND EXTERNAL DEM DATA
}

\author{
Qinghua Xie ${ }^{\text {a,b }}$, Changcheng Wang a,*, Jianjun Zhu ${ }^{\text {a }}$, Haiqiang Fu ${ }^{\text {a }}$, Chaohui Wang a \\ ${ }^{a}$ School of Geosciences and Info-Physics, Central South University, Changsha, China- (csuxqh, wangchangcheng)@csu.edu.cn \\ b Institute for Computing Research (IUII), University of Alicante, Alicante, Spain- csuxqh@ gmail.com
}

\section{Commission VI, WG VI/4}

KEY WORDS: Forest height retrieval; Polarimetric synthetic aperture radar interferometry (PolInSAR); Sloped-Random volume over ground(S- RVoG); Dual-baseline.

\begin{abstract}
:
In recent years, a lot of studies have shown that polarimetric synthetic aperture radar interferometry (PolInSAR) is a powerful technique for forest height mapping and monitoring. However, few researches address the problem of terrain slope effect, which will be one of the major limitations for forest height inversion in mountain forest area. In this paper, we present a novel forest height retrieval algorithm by integration of dual-baseline PolInSAR data and external DEM data. For the first time, we successfully expand the S-RVoG (Sloped-Random Volume over Ground) model for forest parameters inversion into the case of dual-baseline PolInSAR configuration. In this case, the proposed method not only corrects terrain slope variation effect efficiently, but also involves more observations to improve the accuracy of parameters inversion. In order to demonstrate the performance of the inversion algorithm, a set of quad-pol images acquired at the P-band in interferometric repeat-pass mode by the German Aerospace Center (DLR) with the Experimental SAR (E-SAR) system, in the frame of the BioSAR2008 campaign, has been used for the retrieval of forest height over Krycklan boreal forest in northern Sweden. At the same time, a high accuracy external DEM in the experimental area has been collected for computing terrain slope information, which subsequently is used as an inputting parameter in the S-RVoG model. Finally, in-situ ground truth heights in stand-level have been collected to validate the inversion result. The preliminary results show that the proposed inversion algorithm promises to provide much more accurate estimation of forest height than traditional dualbaseline inversion algorithms.
\end{abstract}

\section{INTRODUCTION}

Forest height, as an important forest biophysical parameter, is useful for forest management, biomass inversion and ecosystem modelling (Houghton et al, 2009). In the past few decades, amount of studies have shown that Polarimetric synthetic aperture radar interferometry (PolInSAR) is a promising new technology for forest height inversion from region scale to global scale using Random volume over ground (RVoG) model(Papathanassiou and Cloude, 2001; Cloude and Papathanassiou, 2003). The inversion performance has been implemented for various forest types based on airborne and spaceborne fully polarimetric SAR platform with different frequencies (Fu et al., 2015; Garestier et al., 2011, 2008; Hajnsek et al., 2009; López-Martínez et al., 2011; LopezSanchez et al., 2012; Praks et al., 2007; Song et al., 2014; Xie et al., 2014; Zhu et al., 2014). However, most of published researches before focus on test sites with relatively flat terrain condition and can obtain good inversion results. Few studies address the impact of terrain slope on forest height inversion, which will be a key limitation factor for the practical development of this technology. Recently, Lu et al. (2013) propose a slope random volume over ground (S-RVoG) model, which accounts for range terrain slope and successfully extend the RVoG model by aligning the reference frame. The proposed model has been validated with three-stage algorithm with simulated PolInSAR data. Thereafter, Xie et al. (2015) implement a lot of simulated tests and a real test based on ESAR P-band PolInSAR data using S-RVoG model. The results have shown this inversion model can effectively improve the inversion performance in forest area with relatively steep terrain condition. One limitation of this model is it still exist the assumption about minimum ground to volume scattering ratio in one of the observed polarisation channels. Another limitation is that it need input slope information into the inversion model, which can be acquired from external DEM or derived DEM by InSAR technology itself.

In this paper, we present a novel forest height retrieval frame by integration of dual-baseline PolInSAR data and external DEM data. We successfully expand the S-RVoG model from single baseline configuration to dual baseline mode. Then we adopt the robust parameters estimation algorithm based on dual baseline PolInSAR data proposed by (Cloude, 2002), which can automatically skip the assumption about the minimum ground to volume scattering ratio and provide more observation information. In addition, the slope information for parameters inversion should be obtained by using an external DEM. The performance of the inversion algorithm is validated by using dual baseline PolInSAR data acquired by E-SAR airborne system at P-band over Krycklan boreal forest in northern Sweden.

\section{METHODOLOGY}

\subsection{Polarimetric SAR Interferometry}

A full PoInSAR system obtain two sets of full polarimetric data from slightly different position with a baseline. In general, the observations at either end are expressed by a complex scattering

\footnotetext{
* Corresponding author.

E-mail address: wangchangcheng@ @ csu.edu.cn (C. Wang)
} 
matrix $[S]$, which can be written as (Cloude and Papathanassiou, 1998)

$$
[S]=\left[\begin{array}{ll}
S_{H H} & S_{H V} \\
S_{V H} & S_{V V}
\end{array}\right]
$$

where $S_{p q}$ (p, q=H or $\left.\mathrm{V}\right)$ stands for the scattering coefficient with $\mathrm{p}$ transmitted and $\mathrm{q}$ received polarization in the $\mathrm{HV}$ polarimetric basis. Based on the assumption of reciprocity scattering, the polarimetric information can be expressed by the basis vectors defined as(Cloude and Papathanassiou, 1998)

$$
\begin{aligned}
& k=\frac{1}{2} \operatorname{Trace}\left([S] \Psi_{P}\right) \\
& =\frac{1}{\sqrt{2}}\left[\begin{array}{lll}
S_{H H}+S_{V V} & S_{H H}-S_{V V} & 2 S_{H V}
\end{array}\right]^{T}
\end{aligned}
$$

After define vector $w$ as the generalized scattering mechanism in the polarization space, the complex coherence for arbitrary two polarimetric states can be expressed as(Cloude and Papathanassiou, 1998)

$$
\begin{aligned}
\gamma\left(w_{1}, w_{2}\right) & =\frac{\left|\left\langle\left(w_{1}^{* T} k_{1}\right)\left(w_{2}^{{ }^{* T}} k_{2}\right)^{* T}\right\rangle\right|}{\sqrt{\left\langle\left(w_{1}^{* T} k_{1}\right)\left(w_{1}^{* T} k_{1}\right)\right\rangle \sqrt{\left\langle\left(w_{2}^{* T} k_{2}\right)\left(w_{2}^{* T} k_{2}\right)\right\rangle}}} \\
& =\frac{\left|\left\langle w_{1}^{* T}\left[\Omega_{12}\right] w_{2}\right\rangle\right|}{\sqrt{\left\langle\left(w_{1}^{* T}\left[T_{11}\right] w_{2}\right)\right\rangle \sqrt{\left\langle\left(w_{2}^{* T}\left[T_{22}\right] w_{2}\right)\right\rangle}}}
\end{aligned}
$$

Where $\left[T_{11}\right]$ and $\left[T_{22}\right]$ are two individual positive semidefinite Hermitian coherency matrices, which describe the polarimetric information received by both antenna. $\left[\Omega_{12}\right]$ contains the polarimetric interferometric information.

\subsection{RVoG model}

The Random volume over ground (RVoG) model is the most popular physical model in the mode-based forest parameters inversion from PolInSAR observations. In this model, the scene is abstracted as two layers consist of vegetation layer and ground layer. It assumes vegetation layer consist of homogeneous volume of randomly oriented particles and derives the function relationship between polarimetric complex interferometric coherence in arbitrary polarimetric state and forest biophysical parameters. The interferometric coherence $\gamma$ has been defined as(Papathanassiou and Cloude, 2001)

$$
\begin{aligned}
& \gamma(w)=\exp \left(i \phi_{0}\right) \frac{\gamma_{V}\left(\sigma, h_{v}\right)+m(w)}{1+m(w)} \\
& \gamma_{V}\left(\sigma, h_{v}\right)=\frac{2 \sigma\left(\exp \left(2 \sigma h_{v} / \cos \theta+i k_{z} h_{v}\right)-1\right)}{\left(2 \sigma+i k_{z} \cos \theta\right)\left(\exp \left(2 \sigma h_{v} / \cos \theta\right)-1\right)}
\end{aligned}
$$

where $\phi_{0}$ is underlying ground phase, $h_{v}$ denotes forest height. $k_{z}$ is the effective vertical wavenumber, $\theta$ is the incidence angle. $m$ is the effective ground-to-volume amplitude ratio, and $\sigma$ represents a mean extinction coefficient. $\gamma_{V}$ is the volume-only coherence without ground contribution. The geometric reference frame for RVoG model has shown in Figure 1. From this equation, we can note that theoretically complex coherences in different channels should locate on a straight line in the unit complex plane. In addition, the volumeonly coherence shifted by the ground phase $\gamma_{V} \exp \left(i \phi_{0}\right)$ must lie on the line.

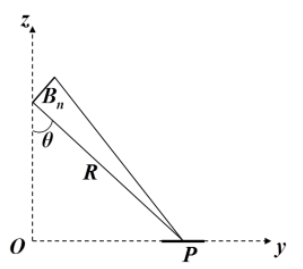

Figure 1. Geometric reference frame for RVoG model

\subsection{S-RVoG model}

Lu et al. (2013) have proposed a sloped random volume over ground(S-RVoG) model accounting for slope. It starts from the similar way of modelling RVoG model and by adjusting the geometric reference frame along local terrain slope (see Figure 2).

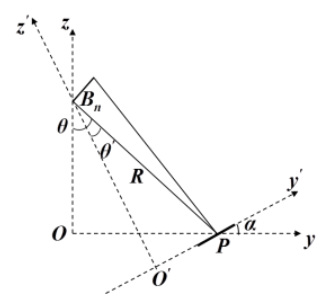

Figure 2. Geometric reference frame for S-RVoG model

Thereafter, the basic form of model is very similar with RVoG model. The difference is the expressions of the volume-only coherence, incidence angle and vertical wavenumber have changed as follow(Lu et al., 2013; Xie et al.,2015)

$$
\begin{gathered}
\gamma_{v}^{\prime}\left(\sigma, h_{v}\right)=\frac{2 \sigma\left(\exp \left(\left(2 \sigma h_{v} / \cos \theta^{\prime}+i k_{z}^{\prime} h_{v}\right) \cos \alpha\right)-1\right)}{\left(2 \sigma+i k_{z}^{\prime} \cos \theta^{\prime}\right)\left(\exp \left(2 \sigma h_{v} \cos \alpha / \cos \theta^{\prime}\right)-1\right)} \\
k_{z}^{\prime}=k_{z} \sin \theta / \sin \theta^{\prime}, \theta^{\prime}=\theta-\alpha
\end{gathered}
$$

\subsection{Dual-Baseline Inversion algorithm with S-RVoG model}

The most advantage of multi-baseline mode is that many parameters keep invariable as the change of baseline. Obviously, it will provide more information and can help improve the condition of parameters inversion. Cloude (2002) propose a robust dual-baseline polarimetric interferometry (DBPI) forest parameters inversion algorithm. In this case, forest height and extinction coefficient are considered as invariable parameters as increase of baseline. For dual-baseline configuration, based on the S-RVOG model, the equations of volume-only coherences for both baseline as follow should be satisfied at the same time.

$$
\begin{aligned}
& \gamma_{V 1}^{\prime}\left(\sigma, h_{v}\right)=\frac{2 \sigma\left(\exp \left(\left(2 \sigma h_{v} / \cos \theta^{\prime}+i k_{z 1}^{\prime} h_{v}\right) \cos \alpha\right)-1\right)}{\left(2 \sigma+i k_{z 1}^{\prime} \cos \theta^{\prime}\right)\left(\exp \left(2 \sigma h_{v} \cos \alpha / \cos \theta^{\prime}\right)-1\right)} \\
& \gamma_{V 2}^{\prime}\left(\sigma, h_{v}\right)=\frac{2 \sigma\left(\exp \left(\left(2 \sigma h_{v} / \cos \theta^{\prime}+i k_{z 2}^{\prime} h_{v}\right) \cos \alpha\right)-1\right)}{\left(2 \sigma+i k_{z 2}^{\prime} \cos \theta^{\prime}\right)\left(\exp \left(2 \sigma h_{v} \cos \alpha / \cos \theta^{\prime}\right)-1\right)}
\end{aligned}
$$

Then, according to the character of the line model, the inversion process described in Cloude (2002) includes: 
1) The least squares line fit separately for the two baselines using complex interferometric coherence associated with different polarization channels.

2) Ground phase of the two baselines $\phi_{1}, \phi_{2}$ estimation by choosing one intersection of the line with the unit circle based on rank ordering of coherence.

3) For the first baseline, stepping along the line of possible volume coherences solutions

4) Obtaining solution pairs of forest height $h_{v}$ and extinction coefficient $\sigma$ by subjecting all possible volume-only coherences solutions in equation for the first baseline.

5) Calculating the corresponding volume-only coherences for the second baseline using solution pairs of $h_{v}, \sigma$;

6) After Phase shifted by $\exp \left(i \phi_{2}\right)$, the predicted coherences can be plotted in the unit complex plane. The true volume coherence will the predicted point lie on the second line or has the minimum distance with the line. The corresponding solution pairs of $h_{v}, \sigma$ are the final solution.

\section{EXPERIMENT}

\subsection{Data Presentation}

In this paper, we collect three scenes of airborne P-band full Polarimetric SAR data acquired by ESAR system in the BioSAR2008 campaign. Then we can construct two polarimetric interferometry pairs, the detailed information has shown in Table 1. From the chart, we can see that the temporal decorrelation effect could be ignored because of small time baseline. The difference between two baselines is not small, and the horizonal baseline are about two times than the first baseline, which can somehow avoid poorly conditioned inversion. The experimental test site locates in Krycklan $\left(64^{\circ} 14^{\prime}\right.$ $\mathrm{N}, 19^{\circ} 46^{\prime} \mathrm{E}$ ), northern Sweden. There is a typical boreal forest area, where the dominating forest type is Scots pine and Norway spruce. In order to obtain accurate slope information, we collect the external DEM with $1 \mathrm{~m}$ grid in the experimental region. For evaluating the inversion result, we acquire the insitu measured forest height data in one typical stands with relatively steep slope level (mean $-14.48 \%$ and std $6.12 \%$ ). The corresponding forest stands vector boundary are shown in Figure 3.

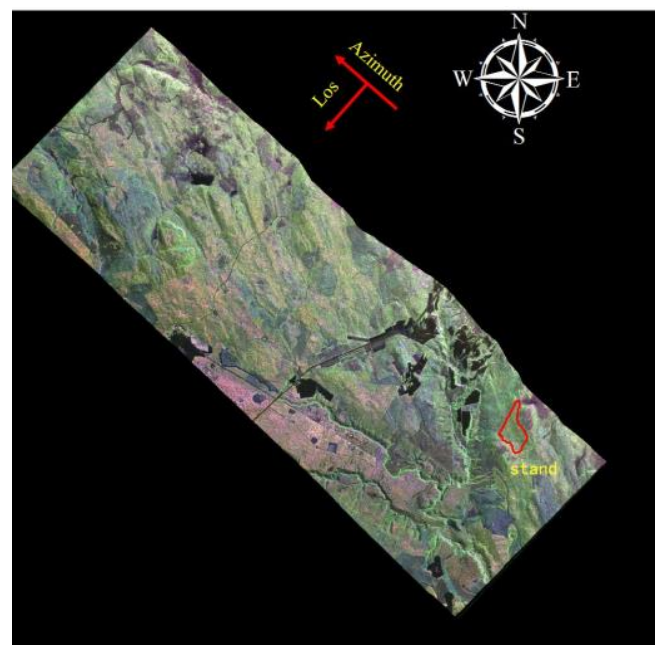

Figure 3. Pauli decomposition RGB image of the test site overlaid by the forest stand vector boundary (red polygon)
Table 1. Description of PolInSAR data

\begin{tabular}{|c|c|c|c|}
\hline Image & Date(UTC) & $\begin{array}{l}\text { Vertical } \\
\text { baseline(m) }\end{array}$ & $\begin{array}{l}\text { Horizontal } \\
\text { baseline }(\mathrm{m})\end{array}$ \\
\hline Master & $\begin{array}{l}\text { 14-OCT- } \\
2008, \\
11: 42: 03\end{array}$ & 0 & 0 \\
\hline Slave1 & $\begin{array}{l}\text { 14-ОСТ- } \\
2008, \\
12: 15: 19\end{array}$ & -1.324 & -16.673 \\
\hline Slave2 & $\begin{array}{l}14-\mathrm{OCT}- \\
2008, \\
12: 52: 35\end{array}$ & -0.202 & -32.354 \\
\hline
\end{tabular}

\subsection{Inversion Result and Discussion}

After finishing image registration based on the geometry frame of common master image, interferometry computation, flatearth-phase removal, we implement $7 \times 7$ boxcar filter for speckle noise reduction. In order to increase effective separation of phase centres and the visible line length in complex plane, the polarisation channels choices in our case are typical linear basis and Pauli basis polarization channels $(\mathrm{HH}, \mathrm{HV}, \mathrm{VV}$, $\mathrm{HH}+\mathrm{VV}, \mathrm{HH}-\mathrm{VV}$ ), and phase diversity optimized polarization channels (PDHigh, PDLow) (Tabb et al., 2002). Then we can obtain 7 complex coherence observations by using $7 \times 7$ boxcar windows for every pixel. After that, we can test the proposed inversion algorithm. Figure 4 shows the inversion process for one case of pixels in test area. The one in all predicated phase shifted volume-only coherences (black cross) in the second baseline calculated from possible volume-only coherences (blue cross) in the first baseline, which locates nearest to the fit line of second baseline should be the final solution of volume-only coherence. Thereafter, we can obtain the final estimation of forest height.

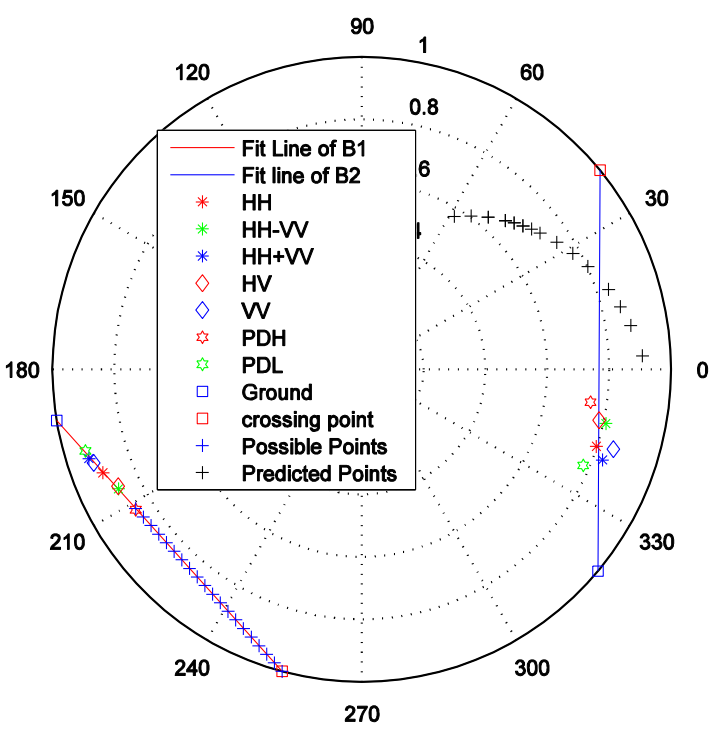

Figure 4. Dual-baseline volume-only coherence estimation

In order to validate the efficiency of the propose inversion algorithm, we adopt some other traditional methods. The core idea of inversion algorithm is all based on three-stage algorithm. The difference come from the different baseline and inversion model. Therefore, the inversion methods includes 
types of RVoG-B1, SRVoG-B1, RVoG-B2, SRVoG-B2, RVoG-DBPI, SRVoG-DBPI. The result of mean forest height based on these methods are shown in Figure 5.

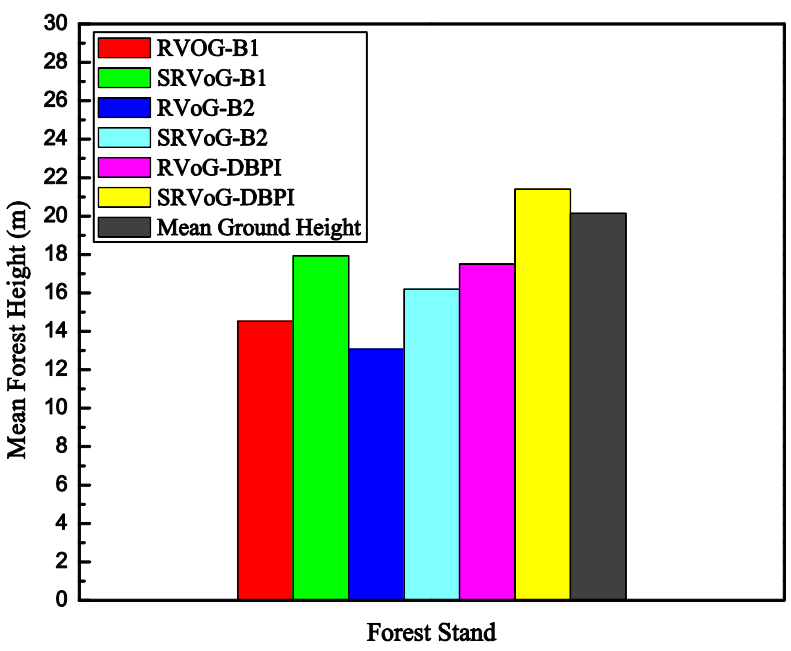

Figure 5. Results of Forest height estimation in the forest stand

From these results, we can see that:

1) For the single baseline case, the result based on S-RVoG model has better performance than RVoG model, the difference is about $3 \mathrm{~m}$. It indicates that the S-RVoG model can correct terrain distortion. The performance of the first baseline shows a little improvement than the second baseline. A possible reason is because the longer baseline will bring more serious spatial decorrealtion, although it will improve the sensitivity of height measurement. The approximate choice of baseline need further investigate.

2) For the dual-baseline case, it also shows that the S-RVoG model could provide more accurate results. In addition, by adding another baseline, the results have shown more or less improvements compared with single baseline case.

\section{CONCUSION}

In this paper, we present a novel dual-baseline forest height inversion algorithm based on S-RVoG model from dualbaseline PolInSAR data and external DEM data. The proposed algorithm promise to correct the range slope effect and free the assumption of minimum ground to volume amplitude ratio in one of the observed polarisation channels. Experiments based on airborne PolInSAR data have shown that the proposed algorithm could provide more accurate parameters inversion result than other traditional methods.

\section{ACKNOWLEDGEMENTS}

This work has been financed by Nature Science Foundation of China (No. 41274010, 41371335), Postgraduate Autonomous Exploration Project of Central South University (NO. 2013zzts055), China Scholarship Council (No.201406370079), Hunan Provincial Innovation Foundation for Postgraduate (No. 150140004). The authors would like to thank both German Aerospace Center (DLR) for E-SAR data and Swedish University of Agricultural Sciences (SLU) for providing Ground-truth data under European Space Agency (ESA) project (NO.14751).

\section{REFERENCES}

Houghton R.A., Hall F.G., Goetz S.J., 2009. Importance of biomass in the global carbon cycle, J Geophys Res., 114, pp. 113.

Cloude, S.R., 2002. Robust parameter estimation using dual baseline polarimetric SAR interferometry. IEEE Int. Geosci. Remote Sens. Symp. 2(C), pp. 838-840.

Cloude, S.R., Papathanassiou, K.P., 2003. Three-stage inversion process for polarimetric SAR interferometry. IEE Proc. - Radar, Sonar Navig. 150(3), pp.125-133.

Cloude, S.R., Papathanassiou, K.P., 1998. Polarimetric SAR Interferometry. IEEE Trans. Geosci. Remote Sens. 36(5), pp. $1551-1565$.

Fu, H., Wang, C., Zhu, J., Xie, Q., Zhao, R., 2015. Inversion of vegetation height from PolInSAR using complex least squares adjustment method. Sci. China Earth Sci. 58(6), pp. 10181031.

Garestier, F., Dubois-Fernandez, P., Champion, I., Le Toan, T., 2011. Pine forest investigation using high resolution P-band Pol-InSAR data. Remote Sens. Environ. 115(11), pp. 28972905.

Garestier, F., Dubois-Fernandez, P.C., Papathanassiou, K.P., 2008. Pine forest height inversion using single-pass X-band PolInSAR data. IEEE Trans. Geosci. Remote Sens. 46(1),pp. 59-68.

Hajnsek, I., Kugler, F., Lee, S.K., Papathanassiou, K.P., 2009. Tropical-forest-parameter estimation by means of Pol-InSAR: The INDREX-II campaign, IEEE Trans. Geosci. Remote Sens. 47(2), pp. 481-493.

López-Martínez, C., Fàbregas, X., Pipia, L., 2011. Forest parameter estimation in the Pol-InSAR context employing the multiplicative-additive speckle noise model. ISPRS J. Photogramm. Remote Sens. 66(5), pp. 597-607.

Lopez-Sanchez, J.M., Hajnsek, I., Ballester-Berman, J.D., 2012. First demonstration of agriculture height retrieval with polinsar airborne data. IEEE Geosci. Remote Sens. Lett. 9(2), pp. 242246.

Lu, H., Suo, Z., Guo, R., Bao, Z., 2013. S-RVoG model for forest parameters inversion over underlying topography. Electron. Lett. 49(9), pp. 618-620.

Papathanassiou, K.P., Cloude, S.R., 2001. Single-baseline polarimetric SAR interferometry. IEEE Trans. Geosci. Remote Sens. 39(11), pp. 2352-2363.

Praks, J., Kugler, F., Papathanassiou, K.P., Hawsek, I., Hallikainen, M., 2007. Height estimation of boreal forest: Interferometric model-based inversion at L- and X-band versus HUTSCAT profiling scatterometer. IEEE Geosci. Remote Sens. Lett. 4(3), pp. 466-470.

Song, G., Wang, C., Fu H., Xie, Q., 2014. A Novel Vegetation Height Inversion Method Based on Polarimetric Interferometric Covariance Matrix Decomposition. Acta Geodaeticaet Cartographica Sinica, 43(6), pp. 613-636. 
Tabb M., Orrey J., Flynn T., Carande R.,2002. Phase diversity: A decomposition for vegetation parameter estimation using polarimetric SAR interferometry, in: EUSAR 2002, pp. 721725.

Xie Q., Wang C., Zhu J., Fu H., 2015, Forest Height Inversion by Combining S-RVOG Model with Terrain Factor and PD Coherence Optimization. Acta Geodaeticaet Cartographica Sinica, 44(6), pp. 686-693.

Xie, Q., Zhu, J., Wang, C., Fu, H., 2014. Boreal forest height inversion using E-SAR PolInSAR data based coherence optimization methods and three-stage algorithm, in: 2014 Third International Workshop on Earth Observation and Remote Sensing Applications (EORSA). pp. 145-150.

Zhu J., Xie Q., Zuo T., Wang C., Xie J. 2014, Criterion of complex least squares adjustment and its application in tree inversion with PolInSAR data. Acta Geodaeticaet Cartographica Sinica, 43(1), pp. 45-51. 